\title{
Erratum to: DNA-chitosan cross-linking and photografting to cotton fabrics to improve washing fastness of the fire-resistant finishing
}

\author{
Annalisa Casale • Francesca Bosco - Giulio Malucelli • Chiara Mollea • Monica Periolatto
}

Published online: 3 November 2016

(C) Springer Science+Business Media Dordrecht 2016

Erratum to: Cellulose

DOI 10.1007/s10570-016-1067-y

Unfortunately, in the original publication of the article, the given name and the family name of all the authors in the author group have been reversed. This has been rectified in this erratum.

The online version of the original article can be found under doi:10.1007/s10570-016-1067-y.

A. Casale - F. Bosco - C. Mollea

Dipartimento di Scienza Applicata e Tecnologia,

Politecnico di Torino, C.so Duca degli Abruzzi, 24,

10129 Turin, Italy

G. Malucelli

Dipartimento di Scienza Applicata e Tecnologia,

Politecnico di Torino, Viale T. Michel 5,

15121 Alessandria, Italy

M. Periolatto $(\varangle)$

Fakultät für Naturwissenschaften und Technik, Freie

Universität Bozen, Universitätsplatz, 5, 39100 Bozen,

Italy

e-mail: monica.periolatto@unibz.it 